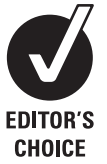

See Editorial Commentary, p 1184

${ }^{1}$ Gertrude H Sergievsky Center, Columbia University Medical Center, New York, NY, USA and the Taub Institute on Alzheimer Disease and the Aging Brain, Columbia University Medical Center, New York, New York, USA ; ${ }^{2}$ Harlem Hospital Center Columbia University, College of Physicians and Surgeons, New York, New York, USA;

${ }^{3}$ Department of Neurology, The Neurological Institute of New York, Columbia University Medical Center, New York, New York, USA; ${ }^{4}$ Department of Health Sciences, Lehman College, City University of New York, New York, New York, USA; ${ }^{5}$ College of Dental Medicine, Section of Oral and Diagnostic Sciences, Division of Periodontics, Columbia University Medical Center, New York, New York, USA; ${ }^{6}$ Stroke Division, Department of Neurology, The Neurological Institute of New York, Columbia University Medical Center, New York, New York, USA; ${ }^{7}$ Evelyn F McKnight Center for Age-related Memory Loss, Division of Cognitive Disorders, Department of Neurology, Miller School of Medicine, University of Miami, Miami, Florida, USA

Correspondence to: Dr J M Noble, Harlem Hospital Center, Columbia College of Physicians and Surgeons, Department of Neurology, 506 Lenox Ave, New York, NY 10037, USA; jn2054@columbia. edu

Received 29 January 2009 Revised 20 March 2009 Accepted 24 March 2009 Published Online First 5 May 2009

\title{
Periodontitis is associated with cognitive impairment among older adults: analysis of NHANES-III
}

\author{
J M Noble, ${ }^{1,2,3}$ L N Borrell, ${ }^{4}$ P N Papapanou, ${ }^{5}$ M S V Elkind, ${ }^{3,6}$ N Scarmeas, ${ }^{1,3}$ \\ C B Wright ${ }^{7}$
}

\begin{abstract}
Background: Periodontitis is ubiquitous and associated with serological evidence of exposure to periodontal organisms, systemic inflammation and vascular disease. Dementia is a major public health problem likely related to a complex interaction between genetics and diseases associated with systemic inflammation, including diabetes, smoking and stroke.
\end{abstract}

Methods: To assess relationships between systemic exposure to periodontal pathogens and cognitive test outcomes, data were analysed from the Third National Health and Nutrition Examination Survey (NHANES-III), a nationally representative cross sectional observational study among older adults. We included 2355 participants $\geqslant 60$ years who completed measures of cognition and Poryphyromonas gingivalis IgG. Using SUDAAN, logistic regression models examined the association of $P$ gingivalis $\lg \mathrm{G}$ with cognitive test performance.

Results: Poor immediate verbal memory $(<5 / 9$ points) was prevalent in $5.7 \%$ of patients, and $6.5 \%$ overall had impaired delayed recall $(<4 / 9)$; $22.1 \%$ had difficulty with serial subtractions $(<5 / 5$ trials correct). Individuals with the highest $P$ gingivalis IgG (>119 ELISA Units (EU)) were more likely to have poor delayed verbal recall (OR 2.89, $95 \% \mathrm{Cl} 1.14$ to 7.29 ) and impaired subtraction (OR $1.95,95 \% \mathrm{Cl} 1.22$ to 3.11$)$ than those with the lowest ( $\leqslant 57 \mathrm{EU}$ ), with dose-response relationships for both ( $p$ trend, delayed memory $=0.045$, subtraction $=0.04$ ). After adjusting for socioeconomic and vascular variables, these relationships remained robust for the highest $P$ gingivalis IgG group (delayed verbal memory OR 3.01 (95\% Cl 1.06 to 8.53); subtraction OR 2.00 (95\% Cl 1.19 to 3.36)). In contrast, immediate verbal memory was not significantly associated with $P$ gingivalis.

Conclusion: A serological marker of periodontitis is associated with impaired delayed memory and calculation. Further exploration of relationships between oral health and cognition is warranted.

Oral health problems, including periodontal disease, caries, edentulism and infrequent preventative care, become more prevalent with increasing age. ${ }^{12}$ Periodontitis and caries are the two predominant causes of tooth loss and reflect similar risk factors, including inattention to care; periodontitis is more common than caries among adults. ${ }^{34}$ Estimates of adult prevalence of clinical periodontitis vary from $20 \%$ to greater than $80 \%, 5$ and differences in prevalence estimates likely depend on clinical markers used for disease definition.

Periodontitis is a chronic, potentially transmissible oral biofilm infection. ${ }^{67}$ Exposure to periodontal pathogens is ubiquitous in older adults, ${ }^{8}$ with a large proportion exposed by adolescence. ${ }^{9}$ A systemic host response to periodontitis is evidenced by serum antibodies to common periodontal bacteria, ${ }^{8}$ such as Porphyromonas gingivalis (a pathogen causally associated with periodontitis), ${ }^{6}$ plus elevations in serum inflammatory markers interleukin $6^{10}$ and $C$ reactive protein. ${ }^{11}$ In addition to epidemiological associations, treatment of periodontal disease decreases serum levels of interleukin 6 and $\mathrm{C}$ reactive protein. ${ }^{11}$

Epidemiological evidence supports an association between stroke and serum antibody measures to $P$ gingivalis. ${ }^{12} P$ gingivalis is associated with accelerated aortic atherogenesis ${ }^{13}$ and increased carotid artery intimal-medial thickness. ${ }^{14}$ Risk factors for stroke and dementia, including diabetes, obesity and smoking, have a similar systemic inflammatory profile to periodontitis ${ }^{15} 16$ and suggest that they could play similar roles in a final common pathway of atherogenesis related to systemic inflammation. ${ }^{15}$

Despite the association of periodontitis with stroke and shared risk factors between stroke and dementia, ${ }^{17}$ to our knowledge, no epidemiological studies have investigated periodontitis relative to cognition. We hypothesised that periodontal disease is a risk factor for poor cognition. Thus we investigated whether periodontitis, as defined by a serological marker, is independently associated with cognitive test performance in older adults in a nationally representative US sample, before and after controlling for potential socioeconomic and vascular confounders.

\section{METHODS}

\section{Source of data}

The Third National Health and Nutrition Examination Survey (NHANES-III) was a cross sectional nationwide health survey of the USA, performed between 1988 and 1994 by the National Center for Health Statistics. NHANES-III enrolled 33994 persons aged 2 months and older using a stratified multistage probability sampling design.

\section{Inclusion criteria}

During the second phase of enrolment (1991-1994), 9371 persons had serum analysis for immunoglobulin levels of $P$ gingivalis, ${ }^{18}$ with $2531 \geqslant 60$ years of age. Of these, persons with both cognitive evaluations and serum analysis for these pathogens $(n=2355)$ were included in this analysis.

\section{Study variables}

Serum $P$ gingivalis IgG was chosen for study to capture evidence of systemic exposure to a 
common periodontal disease causing pathogenic bacterium with well described pathogenicity ${ }^{8}$ and associations with systemic disease and stroke. Antibody measurements were reported in ELISA units of IgG (EU). To examine for possible dose-response relationships of $P$ gingivalis and cognition, we created four ranges of $P$ gingivalis $\operatorname{IgG}$ based on the only known report relating periodontitis severity to $P$ gingivalis $\operatorname{IgG} .{ }^{8}$ That report from the Atherosclerosis Risk in Communities Study (ARIC, $\mathrm{n}=1673$ ) had similar demographics to the NHANES-III subjects studied here and reported mean $P$ gingivalis IgG for healthy individuals of $53.8 \mathrm{EU}$ (SD 9.1), mild periodontitis 60.9 EU (SD 8.4), moderate periodontitis $69.4 \mathrm{EU}$ (SD 5.5) and severe periodontitis 168.4 (SD 9.5) ( $p<0.0001$, determined by nonparametric rank scores from general linear models for overall significance after having $\mathrm{p}<0.05$ for the Hotelling $\mathrm{T}^{2}$ statistic for multiple comparisons of 17 periodontal bacteria serum titres). ${ }^{8}$ To capture the relationship of increasing $P$ gingivalis $\operatorname{IgG}$ associated with increasing periodontitis severity, we used the midpoint between each of these $P$ gingivalis IgG means to create cut-off points for four $P$ gingivalis IgG groups: $\leqslant 57 \mathrm{EU}$ (referent), 58-65 EU, 66-119 EU and >119 EU (highest).

Three cognitive tests were measured in NHANES-III: an immediate and delayed logical verbal memory test from the East Boston Memory Test, ${ }^{19}$ a three word registration/memory task ("apple," "table" and "penny") and five serial subtractions by intervals of three. Consistent with previous NHANES-III reports, ${ }^{20} 21$ a summary score of less than 4 out of a possible 9 points in total (0-6 points from paragraph/story memory, plus $0-3$ points from three word recall) was considered impaired. For immediate memory (registration), again using a summary score of logical memory and three word task, we considered less than 5 out of 9 points (10th percentile) to be impaired. For the test of serial subtractions, any miscalculation during the five trials was considered impaired. We also initially explored a clinical definition of periodontitis ${ }^{22}$ relative to delayed memory but found no association (data not shown).

A comprehensive history was taken, including medical history, medication use and self-reported sociodemographic factors. Race-ethnicity included data from the three major groups, as collected in the survey: non-Hispanic White, nonHispanic Black and Mexican-American. Annual individual income was categorised into three groups: $\leqslant \$ 14999$, $\$ 15000-24999$ and $>\$ 25000$. Health insurance status was defined by active health insurance within the last month (private company, Medicare, Medicaid or military). Years of education were categorised as $<12$ years (less than high school education), 12 years (equivalent to completion of high school) and $>12$ years of (at least some education beyond high school). Smoking status was specified as never, current or former smokers.

Coronary artery disease (CAD) was defined by history of myocardial infarction or anginal symptoms (pain or discomfort in the chest while walking uphill that abates with rest). Congestive heart failure (CHF) was based on a history of a physician informing the patient of CHF. Stroke was defined as a self-reported history of stroke or if the subject had been informed by a physician of stroke. Diabetes mellitus was defined by self-report of diabetes; women with only a history of gestational diabetes were not considered diabetic. Hypertension was defined as present if the participant self-reported hypertension, used anti-hypertensive medications or had measured systolic blood pressure $>130 \mathrm{~mm} \mathrm{Hg}$ or diastolic blood pressure $>85 \mathrm{~mm} \mathrm{Hg}$. This more liberal assessment of blood pressure is consistent with that of the metabolic syndrome ${ }^{23}$ and was used in order to minimise the potential effect of this possible confounder.

\section{Statistical methods}

Descriptive statistics for selected characteristics and prevalence of the outcomes of interest were estimated. To determine significance of differences, $t$ tests for comparison of means of continuous variables were used. To determine the strength of the association between $P$ gingivalis $\operatorname{IgG}$ and cognitive test performance before and after controlling for selected covariates, logistic regression models were fitted. All data management was done using SAS v9.1 (SAS/STAT 9.1 User's Guide, 2004; SAS Institute Inc, Cary, North Carolina, USA). All analyses were

Table 1 Distribution and prevalence of selected characteristics in NHANES-III adults included in the analyses (unweighted $\mathrm{n}=2355$ )

\begin{tabular}{|c|c|}
\hline Characteristic & Overall $(\%)$ \\
\hline \multicolumn{2}{|l|}{ Sex } \\
\hline Women & 57.3 \\
\hline Men & 42.7 \\
\hline \multicolumn{2}{|l|}{ Race-ethnicity } \\
\hline Non-Hispanic White & 89.2 \\
\hline Non-Hispanic Black & 8.3 \\
\hline Mexican-American & 2.5 \\
\hline \multicolumn{2}{|l|}{ Active health insurance } \\
\hline Yes & 98.7 \\
\hline No & 1.3 \\
\hline \multicolumn{2}{|l|}{ Education } \\
\hline$<12$ years & 38.5 \\
\hline 12 years & 32.5 \\
\hline$>12$ years & 28.9 \\
\hline \multicolumn{2}{|l|}{ Annual income } \\
\hline$\leqslant \$ 14999$ & 31.4 \\
\hline$\$ 15000-24999$ & 26.2 \\
\hline$>\$ 25000$ & 42.4 \\
\hline \multicolumn{2}{|l|}{ Smoking history } \\
\hline Non-smokers & 45.8 \\
\hline Former smokers & 40.3 \\
\hline Active smokers & 13.8 \\
\hline \multicolumn{2}{|l|}{ CAD } \\
\hline Yes & 15.4 \\
\hline No & 84.6 \\
\hline \multicolumn{2}{|l|}{$\mathrm{CHF}$} \\
\hline Yes & 6.5 \\
\hline No & 93.5 \\
\hline \multicolumn{2}{|l|}{ Prior stroke } \\
\hline Yes & 7.1 \\
\hline No & 92.9 \\
\hline \multicolumn{2}{|l|}{ Diabetes } \\
\hline Yes & 11.9 \\
\hline No & 88.1 \\
\hline \multicolumn{2}{|l|}{ Hypertension } \\
\hline Yes & 74.5 \\
\hline No & 25.5 \\
\hline \multicolumn{2}{|l|}{ Dentate status } \\
\hline Completely edentulous & 29.3 \\
\hline Edentulous in 1 arch & 14.5 \\
\hline Some natural teeth present & 56.2 \\
\hline \multicolumn{2}{|l|}{$P$ gingivalis $\lg \mathrm{G}(\mathrm{EU})$} \\
\hline$(\leqslant 57)$ & 7.9 \\
\hline$(58-65)$ & 18.9 \\
\hline (66-119) & 54.1 \\
\hline$(>119)$ & 19.1 \\
\hline
\end{tabular}

$\mathrm{CAD}$, coronary artery disease; $\mathrm{CHF}$, congestive heart failure. 
Table 2 Mean $P$ gingivalis IgG level for selected population characteristics: NHANES III

\begin{tabular}{|c|c|c|c|c|}
\hline Characteristic & $\begin{array}{l}\text { Mean } P \text { gingivalis } \lg G \\
\text { (EU) }(95 \% \mathrm{Cl})\end{array}$ & p Value* & & \\
\hline Overall & $117.2(103.6-131.1)$ & & & \\
\hline \multicolumn{5}{|l|}{ Age } \\
\hline$\leqslant 72$ years & $117.0(103.3-130.6)$ & 0.62 & & \\
\hline$>72$ years & $121.3(102.6-139.9)$ & & & \\
\hline \multicolumn{5}{|l|}{ Sex } \\
\hline Men & $127.1(111.2-143.1)$ & 0.03 & & \\
\hline Women & $112.1(97.8-126.3)$ & & & \\
\hline Race-ethnicity & & $W$ vs $B$ & W vs $M$ & $B$ vs $M$ \\
\hline Non-Hispanic White (W) & $105.7(96.3-115.0)$ & $<0.01$ & 0.05 & 0.89 \\
\hline Non-Hispanic Black (B) & $220.8(152.7-288.9)$ & & & \\
\hline Mexican-American (M) & $212.1(104.9-319.2)$ & & & \\
\hline \multicolumn{5}{|l|}{ Active health insurance } \\
\hline Yes & $118.0(104.6-131.5)$ & 0.15 & & \\
\hline No & 150.5 (103.4-197.6) & & & \\
\hline Education & & E vs $H S$ & E vs $C$ & $\mathrm{HS}$ vs $\mathrm{C}$ \\
\hline$<12$ years $(E)$ & $121.1(101.0-141.3)$ & 0.49 & 0.61 & 0.88 \\
\hline 12 years (HS) & $113.3(96.7-129.9)$ & & & \\
\hline$>12$ years $(C)$ & $114.8(97.7-131.8)$ & & & \\
\hline Annual income & & $L$ vs $M$ & $\mathrm{~L}$ vs $\mathrm{Hi}$ & $\mathrm{M}$ vs $\mathrm{Hi}$ \\
\hline$\leqslant \$ 14999$ (L) & $138.2(114.1-162.4)$ & 0.01 & 0.01 & 0.56 \\
\hline$\$ 15000-24999$ (M) & $111.5(93.6-129.5)$ & & & \\
\hline$>\$ 25000(\mathrm{Hi})$ & $106.5(95.1-117.8)$ & & & \\
\hline Smoking history & & $A$ vs $F$ & A vs $N$ & F vs $N$ \\
\hline Active smokers (A) & $99.1(87.7-110.5)$ & 0.01 & $<0.01$ & 0.29 \\
\hline Former smokers (F) & $116.4(101.1-131.7)$ & & & \\
\hline Non-smokers (N) & $126.1(108.1-144.1)$ & & & \\
\hline \multicolumn{5}{|l|}{ CAD } \\
\hline Yes & $104.1(91.4-116.8)$ & 0.02 & & \\
\hline No & $121.0(106.5-135.6)$ & & & \\
\hline \multicolumn{5}{|l|}{ CHF } \\
\hline Yes & $124.3(98.9-149.7)$ & 0.59 & & \\
\hline No & $118.1(104.8-131.4)$ & & & \\
\hline \multicolumn{5}{|l|}{ Prior stroke } \\
\hline Yes & $143.0(98.9-187.2)$ & 0.23 & & \\
\hline No & $116.7(103.6-129.9)$ & & & \\
\hline \multicolumn{5}{|l|}{ Diabetes } \\
\hline Yes & 139. 4 (101.6-177.3) & 0.66 & & \\
\hline No & $115.7(103.0-128.4)$ & & & \\
\hline \multicolumn{5}{|l|}{ Hypertension } \\
\hline Yes & $125.4(108.8-142.0)$ & $<0.01$ & & \\
\hline No & $99.4(88.0-110.8)$ & & & \\
\hline Dentate status & & EA vs E1 & EA vs $T$ & E1 vs T \\
\hline Edentulous (EA) & $80.7(73.2-88.2)$ & 0.02 & $<0.01$ & 0.01 \\
\hline Edentulous in 1 arch (E1) & $105.9(85.8-125.9)$ & & & \\
\hline At least some natural teeth present $(\mathrm{T})$ & $143.6(122.3-164.8)$ & & & \\
\hline
\end{tabular}

${ }^{*} \mathrm{p}$ values derived from $\mathrm{t}$ test comparison of means of $P$ gingivalis IgG by population characteristic. $\mathrm{CAD}$, coronary artery disease; CHF, congestive heart failure; EU, ELISA unit.

performed with SUDAAN (SUDAAN Language Manual, Release 9.0, 2004; Research Triangle Institute, North Carolina, USA), which takes into account the complex sampling design used in NHANES-III yielding unbiased standard error estimates.

\section{RESULTS}

Mean age of the study participants was 70.8 years (95\% CI 70.0 to 71.6 ); $57 \%$ were women (table 1). Overall, the mean $P$ gingivalis IgG level was 117.2 EU (95\% CI 103.6 to 131.1). Mean $P$ gingivalis IgG significantly differed by sex, race, income, smoking history, dental health status, $\mathrm{CAD}$ and hypertension (table 2).

Poor immediate verbal memory (registration) was prevalent in $5.7 \%$ of patients, and overall $6.5 \%$ had impaired verbal memory; $22.1 \%$ had some difficulty with serial subtractions. Mean $P$ gingivalis IgG was higher among those with impaired performance for each of the three cognitive tests (table 3). Immediate verbal memory (registration) was not significantly associated with high $P$ gingivalis IgG in any model (table 4$)$. In unadjusted models, individuals in the highest $P$ gingivalis $\operatorname{IgG}$ group (>119 EU) were more likely to have poor delayed verbal memory (OR 2.89, 95\% CI 1.14 to 7.29 ) and impaired subtraction (OR 1.95, 95\% CI 1.22 to 3.11) than those in the lowest group ( $\leqslant 57 \mathrm{EU}$ ), with apparent dose-response relationships for both ( $p$ trend, delayed memory $=0.045$; $p$ trend, subtraction $=0.04)($ tables 5,6$)$.

We then explored potential effects on the relationship between $P$ gingivalis IgG and cognitive tests, initially by age, 
Table 3 Cognitive test performance relative to $P$ gingivalis $\lg \mathrm{G}$

\begin{tabular}{lcll}
\hline Test & $\begin{array}{l}\text { Overall } \\
(\%)\end{array}$ & $\begin{array}{l}\boldsymbol{P} \text { gingivalis } \mathbf{I g G} \\
\text { (EU) (95\% Cl) }\end{array}$ & p Value* \\
\hline $\begin{array}{l}\text { Immediate verbal memory/registration } \\
\text { (9 possible points) }\end{array}$ & & & \\
$\quad$ Low (0-4 points) & 5.7 & $164.3(78.3-250.3)$ & 0.24 \\
$\quad$ High (5-9 points) & & $113.6(100.7-126.5)$ & \\
$\begin{array}{l}\text { Delayed verbal memory (9 possible } \\
\text { points) }\end{array}$ & & & \\
$\quad$ Low (0-3 points) & 6.9 & $155.3(87.4-223.2)$ & 0.23 \\
$\quad$ High (4-9 points) & & $114.6(101.6-127.7)$ & \\
$\begin{array}{l}\text { Serial 3 subtraction test (5 possible } \\
\text { points) }\end{array}$ & & & \\
$\quad$ Low (0-4 points) & 22.1 & $132.3(114.3-150.4)$ & 0.046 \\
$\quad$ High (5 points) & & $114.8(100.6-129.0)$ & \\
\hline $\begin{array}{l}\text { *p values derived from t test comparison of means of } P \text { gingivalis lgG by population } \\
\text { characteristic. }\end{array}$ & &
\end{tabular}

sex and education, which did not appreciably affect the relationship between $P$ gingivalis IgG and delayed memory or subtraction (model 1, tables 5, 6). Additionally adjusting for other socioeconomic confounders (insurance status, race and income) led to marked attenuation of the relationship between the highest $P$ gingivalis IgG group and delayed memory (OR $1.81,95 \%$ CI 0.56 to 5.85 , p trend $=0.45$ ) but did not affect the relationship with the subtraction test (model 2, tables 5, 6). Finally, we explored a model additionally including potential vascular confounders hypertension, CAD, CHF, diabetes mellitus, smoking and stroke. Inclusion of vascular variables strengthened the relationship between the highest $P$ gingivalis IgG group and delayed verbal memory (OR 3.01, 95\% CI 1.06 to 8.53) but had minimal effect on the test of subtraction (OR $2.00,95 \%$ CI 1.19 to 3.36). Taken together, these findings suggest that vascular factors are a negative confounder in the relationship of $P$ gingivalis and delayed memory in a model adjusting for socioeconomic factors. Moreover, neither vascular nor socioeconomic factors played an appreciable role in the relationship of $P$ gingivalis $\operatorname{IgG}$ and subtraction test performance.

We also explored potential effect modification of the relationship between $P$ gingivalis $\operatorname{IgG}$ and cognitive tests by age (dichotomised at a median age of 72 years), stroke history and race (given its apparent role as a confounder in the relationship with delayed memory). None of these potential effect modifiers were statistically significant in crude or fully adjusted models for any of the cognitive tests (data not shown).

\section{DISCUSSION}

We identified a cross sectional association between a serological marker of a common periodontitis pathogen and poor cognitive test performance in a large nationally representative sample. Individuals with high levels of $P$ gingivalis IgG had significantly greater odds of impaired verbal memory and subtraction test performance and this finding remained robust when adjusting for potential sociodemographic and vascular confounders. Furthermore, we identified a statistically significant doseresponse relationship between subtraction test performance and increasing $P$ gingivalis $\operatorname{IgG}$ and a similar but non-significant trend regarding delayed verbal memory and $P$ gingivalis $\operatorname{IgG}$. Given these findings, we performed post hoc analyses of $A$ actinomycetemcomitans IgG (the only other periodontal pathogen evaluated in NHANES-III) and clinical periodontitis ${ }^{22}$ relative to all cognitive test outcomes but found no relationship in any models (data not shown), perhaps related to weak associations of $A$ actinomycetemcomitans with systemic disease ${ }^{12}$ and imprecise clinical periodontal measurements in NHANES-III. ${ }^{24}$ Notably, an NHANES-III study found that among those aged 2059 years, markers of periodontitis (gingival bleeding, loss of periodontal attachment and tooth loss) were associated with poor symbol digit substitution test and serial digit learning test performance. However, these same individual clinical measures of periodontitis were not associated with story recall in adjusted models among those aged 70 years and older. ${ }^{25}$

These cross sectional analyses do not allow inferences regarding the directionality of the association of cognition and dental health. A relatively straightforward argument can be made for cognitive impairment leading to poor dental health: persons with impaired cognition could be inattentive to oral hygiene or oral health maintenance as impairment in cognition progresses. ${ }^{26}$ Conversely, worth considering is whether poor oral health could contribute to subsequent cognitive impairment.

Although results presented here are preliminary and inconclusive, a growing body of evidence supports exploration of a possible association between poor oral health and incident dementia. Poor dentition, a late-life marker of earlier oral health conditions such as periodontitis, is associated with both prevalent cognitive impairment ${ }^{2527} 28$ and incident dementia. ${ }^{29-31}$ In addition, at least one randomised trial demonstrated that more intensive dental care was associated to a 1.5 point significantly slower decline in Folstein Mini-Mental Status Examination score after 2 years. ${ }^{32}$

Despite association of stroke with periodontitis, ${ }^{17}{ }^{33}$ stroke did not appear to be a confounder or effect modifier in the relationship between $P$ gingivalis $\operatorname{IgG}$ and cognitive test performance. This could reflect an imprecise assessment of stroke based on self-report, or that the relationship between stroke, periodontitis and memory is masked within a crosssectional study. Alternatively, periodontitis could be related to cognition independent of clinical stroke. Similar to diabetes, hypertension and smoking, ${ }^{34}$ periodontitis is associated with

Table 4 Crude and adjusted odds ratios for $P$ gingivalis IgG and memory tests. Immediate verbal memory/ registration (impaired $<5 / 9$ possible points)

\begin{tabular}{lllll}
\hline \multirow{2}{*}{$\boldsymbol{P}$ gingivalis IgG (EU) } & \multicolumn{4}{l}{ Models for immediate verbal memory OR (95\% CI) } \\
\cline { 2 - 5 }$(\leqslant 57)$ [reference] & 1 & Model 1 & Model 2 & Model 3 \\
$(58-65)$ & $0.99(0.34-2.86)$ & $0.90(0.29-2.80)$ & $0.57(0.18-1.83)$ & 1 \\
$(66-119)$ & $1.63(0.48-5.54)$ & $1.44(0.38-5.42)$ & $1.17(0.29-4.73)$ & $1.99(0.57-6.98)$ \\
$(>119)$ & $2.14(0.62-7.39)$ & $2.02(0.54-7.63)$ & $1.62(0.39-6.80)$ & $2.57(0.75-8.85)$ \\
p Trend & 0.11 & 0.21 & 0.04 & 0.07
\end{tabular}

Crude, association of $P$ gingivalis IgG and cognitive test; Model 1, additionally adjusted for age, sex and education; Model 2, additionally adjusted for race, insurance and income; Model 3, additionally adjusted for history of diabetes mellitus, hypertension, smoking, congestive heart failure, coronary artery disease, stroke and $\mathrm{C}$ reactive protein. 
Table 5 Crude and adjusted odds ratios for $P$ gingivalis $\operatorname{lgG}$ and memory tests. Delayed verbal memory (impaired $<4 / 9$ possible points)

\begin{tabular}{|c|c|c|c|c|}
\hline \multirow[b]{2}{*}{$P$ gingivalis IgG (EU) } & \multicolumn{4}{|c|}{ Models for delayed verbal memory OR $(95 \% \mathrm{CI})$} \\
\hline & Crude & Model 1 & Model 2 & Model 3 \\
\hline$(\leqslant 57)$ [reference] & 1 & 1 & 1 & 1 \\
\hline$(58-65)$ & $1.43(0.67-3.03)$ & $1.40(0.64-3.09)$ & $1.04(0.43-2.50)$ & $1.82(0.88-3.75)$ \\
\hline$(66-119)$ & $2.03(0.80-5.18)$ & $1.94(0.69-5.41)$ & $1.54(0.49-4.81)$ & $2.60(0.91-7.46)$ \\
\hline$(>119)$ & $2.89(1.14-7.29)$ & $3.23(1.19-8.79)$ & $1.81(0.56-5.85)$ & $3.01(1.06-8.53)$ \\
\hline $\mathrm{p}$ Trend & 0.045 & 0.01 & 0.45 & 0.22 \\
\hline
\end{tabular}

Crude, association of $P$ gingivalis IgG and cognitive test; Model 1, additionally adjusted for age, sex and education; Model 2, additionally adjusted for race, insurance and income; Model 3, additionally adjusted for history of diabetes mellitus, hypertension, smoking, congestive heart failure, coronary artery disease, stroke and $\mathrm{C}$ reactive protein.

Table 6 Crude and adjusted odds ratios $(\mathrm{OR})$ for $P$ gingivalis $\lg \mathrm{G}$ and memory tests. Serial subtraction (impaired $<5 / 5$ possible points)

\begin{tabular}{|c|c|c|c|c|}
\hline \multirow[b]{2}{*}{$P$ gingivalis IgG (EU) } & \multicolumn{4}{|c|}{ Models for calculation/attention OR (95\% CI) } \\
\hline & Crude & Model 1 & Model 2 & Model 3 \\
\hline$(\leqslant 57)$ [reference] & 1 & 1 & 1 & 1 \\
\hline$(58-65)$ & $1.49(0.86-2.59)$ & $1.54(0.86-2.76)$ & $1.48(0.69-3.18)$ & $1.57(0.74-3.31)$ \\
\hline$(66-119)$ & $1.42(0.97-2.08)$ & $1.37(0.94-1.98)$ & $1.34(0.77-2.34)$ & $1.36(0.80-2.29)$ \\
\hline$(>119)$ & $1.95(1.22-3.11)$ & $2.02(1.31-3.10)$ & $1.98(1.14-3.42)$ & $2.00(1.19-3.36)$ \\
\hline $\mathrm{p}$ Trend & 0.04 & 0.01 & 0.06 & 0.0498 \\
\hline
\end{tabular}

Crude, association of $P$ gingivalis IgG and cognitive test; Model 1, additionally adjusted for age, sex and education; Model 2, additionally adjusted for race, insurance and income; Model 3, additionally adjusted for history of diabetes mellitus, hypertension, smoking, congestive heart failure, coronary artery disease, stroke and $\mathrm{C}$ reactive protein.

impaired systemic arterial endothelial function, ${ }^{35}$ and the latter has been associated with cerebral white matter hyperintensities, $^{36}$ vascular dementia and Alzheimer's disease. ${ }^{37} 38$ Alternatively, systemic inflammation has been hypothesised to directly influence expression of neurodegenerative disorders such as Alzheimer's disease. ${ }^{39}$

This study has several limitations other than the constraints of cross sectional analysis. Measurable socioeconomic covariates provide a restricted scope of lifelong socioeconomic status and periodontitis could be or lead, at least in part, to residual confounder; indeed, low socioeconomic status is strongly associated with periodontitis in NHANES-III.22 Moreover, persons with low socioeconomic status may have low cognitive reserve, ${ }^{40}$ or relatively worse memory test performance despite similar brain pathology compared with other groups.

Available NHANES-III cognitive tests are another limitation. The cognitive measurements reported here are crude assessments of cognitive test performance and may reflect individual or group differences in test understanding, rather than a true assessment of cognition. The limited scope of these tests also does not clearly inform a potential neuroanatomical basis for impaired test performance, given likely overlapping cognitive domains involved with each task. Furthermore, the precise aetiology of impaired cognitive test performance cannot be known from these data. Nonetheless, the components of the outcome used here have been validated as rigorous tools for screening memory in epidemiological studies. ${ }^{19}$

In an attempt to capture a dose-response relationship between $P$ gingivalis IgG and cognitive test performance, we created $P$ gingivalis IgG groups based on a report from another large multicentre population based American study (ARIC), ${ }^{8}$ which found a strong association between escalating levels of $P$ gingivalis $\operatorname{IgG}$ and clinical periodontitis severity. Use of this schema for creating $P$ gingivalis IgG groups appears plausible but requires validation in other studies. Serum antibodies to periodontal pathogens are strongly associated with worse states of oral health ${ }^{8}$ and remain persistently elevated despite clinical treatment. ${ }^{41}$ Taken together, these findings suggest that serum antibody levels reflect chronic, intermittent exposures of clinical periodontitis, but it is uncertain whether to state that a higher periodontal titre implies higher burden of acute exposures, more recent exposure or more intense response to periodontal pathogens.

Periodontitis is a lifelong, highly prevalent, chronic inflammatory disease associated with stroke, systemic inflammation and endothelial dysfunction. Although our results are preliminary, they suggest that further exploration of relationships between oral health and cognition is warranted.

Acknowledgements: NHANES-III is a publicly available data set. JMN had full access to all of the data in the study and takes responsibility for the integrity of the data and the accuracy of the data analysis.

Funding: This research was supported by Public Health Service Grant No 5-T32NS07153-23 and a grant from Charles L and Ann Lee Saunders Brown (for JMN). PNP has received support for research on the relationship of periodontal treatment and peripheral blood mononuclear cell activation from Colgate-Palmolive and on the relationship of periodontal disease and stage 5 kidney disease from Johnson and Johnson. MSVE has received research support from the National Institutes of Health. In addition, MSVE has received support for research on the relationship of inflammatory markers and recurrent stroke risk in lacunar stroke patients from BMSSanofi Pharmaceutical Partnership and on the relationship of inflammatory markers and recurrent stroke risk from Diadexus Inc.

Competing interests: None.

Provenance and peer review: Not commissioned; externally peer reviewed.

\section{REFERENCES}

1. Miller AJ, Brunelle JA, Carlos JP, et al. Oral health of United States adults. Bethesda, MD: US Department of Health and Human Services, Public Health Service, National Institutes of Health, 1987.

2. Machtei EE, Christersson LA, Grossi SG, et al. Clinical criteria for the definition of "established periodontitis". J Periodontol 1992;63:206-14.

3. Machtei EE, Hausmann E, Dunford R, et al. Longitudinal study of predictive factors for periodontal disease and tooth loss. J Clin Periodontol 1999;26:374-80.

4. Rosling B, Serino G, Hellstrom MK, et al. Longitudinal periodontal tissue alterations during supportive therapy. Findings from subjects with normal and high susceptibility to periodontal disease. J Clin Periodontol Mar 2001;28:241-9. 
5. Burt B. Position paper: epidemiology of periodontal diseases. J Periodontol 2005;76:1406-19.

6. Socransky SS, Haffajee AD, Cugini MA, et al. Microbial complexes in subgingival plaque. J Clin Periodontol 1998:25:134-44.

7. Donlan RM, Costerton JW. Biofilms: survival mechanisms of clinically relevant microorganisms. Clin Microbiol Rev 2002;15:167-93.

8. Offenbacher S, Barros SP, Singer RE, et al. Periodontal disease at the biofilmgingival interface. J Periodontol 2007;78:1911-25.

9. Kulekci G, Leblebicioglub B, Keskina F, et al. Salivary detection of periodontopathic bacteria in periodontally healthy children. Anaerobe 2008;14:49-54.

10. Bretz WA, Weyant RJ, Corby PM, et al. Systemic inflammatory markers, periodontal diseases, and periodontal infections in an elderly population. J Am Geriatr Soc 2005; 53:1532-7.

11. D'Aiuto F, Parkar M, Andreou G, et al. Periodontitis and systemic inflammation: control of the local infection is associated with a reduction in serum inflammatory markers. J Dent Res 2004;83:156-60.

12. Pussinen PJ, Alfthan G, Jousilahti $P$, et al. Systemic exposure to Porphyromonas gingivalis predicts incident stroke. Atherosclerosis 2007:193:222-8.

13. Ford PJ, Gemmell E, Timms P, et al. Anti-P. gingivalis response correlates with atherosclerosis. J Dent Res 2007:86:35-40.

14. Desvarieux M, Demmer RT, Rundek T, et al. Periodontal microbiota and carotid intima-media thickness: the Oral Infections and Vascular Disease Epidemiology Study (INVEST). Circulation 2005:111:576-82.

15. Libby P, Ridker PM, Maseri A. Inflammation and atherosclerosis. Circulation 2002;105:1135-43

16. Yanbaeva DG, Dentener MA, Creutzberg EC, et al. Systemic effects of smoking. Chest 2007;131:1557-66.

17. van Oijen $\mathbf{M}$, de Jong FJ, Witteman JC, et al. Atherosclerosis and risk for dementia. Ann Neurol 2007:61:403-10.

18. Dye BA, Choudhary K, Shea S, et al. Serum antibodies to periodontal pathogens and markers of systemic inflammation. J Clin Periodontol 2005;32:1189-99.

19. Albert M, Smith LA, Scherr PA, et al. Use of brief cognitive tests to identify individuals in the community with clinically diagnosed Alzheimer's disease. Int J Neurosci 1991:57:167-78.

20. Perkins AJ, Hendrie HC, Callahan CM, et al. Association of antioxidants with memory in a multiethnic elderly sample using the Third National Health and Nutrition Examination Survey. Am J Epidemiol 1999:150:37-44.

21. Zhang Y, Heeren T, Curtis Ellison R. Education modifies the effect of alcohol on memory impairment: the third national health and nutrition examination survey. Neuroepidemiology 2005;24:63-9.

22. Borrell LN, Burt BA, Neighbors HW, et al. Social factors and periodontitis in an older population. Am J Public Health 2004:94:748-54.

23. Executive Summary of the Third Report of The National Cholesterol Education Program (NCEP) Expert Panel on Detection, Evaluation, and Treatment of High Blood Cholesterol in Adults (Adult Treatment Panel III). JAMA 2001;285:2486-97.
24. Beck JD, Caplan DJ, Preisser JS, et al. Reducing the bias of probing depth and attachment level estimates using random partial-mouth recording. Community Dent Oral Epidemiol 2006;34:1-10.

25. Stewart R, Sabbah W, Tsakos G, et al. Oral health and cognitive function in the Third National Health and Nutrition Examination Survey (NHANES III). Psychosom Med 2008; 70:936-41.

26. Noble JM, Scarmeas N. Cognitive Impairment. In: Lamster IB, Northridge ME, eds Improving Oral Health for the Elderly. New York: Springer Science \& Business Media 2008.

27. Kim JM, Stewart R, Prince M, et al. Dental health, nutritional status and recentonset dementia in a Korean community population. Int J Geriatr Psychiatry 2007:22:850-5.

28. Stewart R, Hirani V. Dental health and cognitive impairment in an English national survey population. J Am Geriatr Soc 2007:55:1410-14.

29. Gatz M, Mortimer JA, Fratiglioni L, et al. Potentially modifiable risk factors for dementia in identical twins. Alzheimers Dement J Alzheimers Assoc 2006;2:110-17.

30. Kondo K, Niino M, Shido K. A case-control study of Alzheimer's disease in Japansignificance of life-styles. Dementia 1994;5:314-26.

31. Stein PS, Desrosiers M, Donegan SJ, et al. Tooth loss, dementia and neuropathology in the Nun study. J Am Dent Assoc Oct 2007;138:1314-22.

32. Yoneyama T, Yoshida $\mathrm{M}$, Ohrui $\mathrm{T}$, et al. Oral care reduces pneumonia in older patients in nursing homes. J Am Geriatr Soc 2002;50:430-3.

33. Beck JD, Offenbacher S. Systemic effects of periodontitis: epidemiology of periodontal disease and cardiovascular disease. J Periodontol 2005;76(Suppl):2089-100

34. Munzel T, Sinning C, Post F, et al. Pathophysiology, diagnosis and prognostic implications of endothelial dysfunction. Ann Med 2008;40:180-96.

35. Tonetti MS, D'Aiuto F, Nibali $L$, et al. Treatment of periodontitis and endothelia function. N Engl J Med 2007:356:911-20.

36. Hoth KF, Tate DF, Poppas A, et al. Endothelial function and white matter hyperintensities in older adults with cardiovascular disease. Stroke 2007:38:308-12.

37. Vicenzini E, Ricciardi MC, Altieri M, et al. Cerebrovascular reactivity in degenerative and vascular dementia: a transcranial Doppler study. Eur Neurol 2007;58:84-9.

38. Silvestrini M, Pasqualetti $P$, Baruffaldi $R$, et al. Cerebrovascular reactivity and cognitive decline in patients with Alzheimer disease. Stroke 2006;37:1010-15.

39. Perry VH, Cunningham C, Holmes C. Systemic infections and inflammation affect chronic neurodegeneration. Nat Rev Immunol 2007:7:161-7.

40. Stern Y, Albert S, Tang MX, et al. Rate of memory decline in $A D$ is related to education and occupation: cognitive reserve? Neurology 1999;53:1942-7.

41. Papapanou PN, Neiderud AM, Disick E, et al. Longitudinal stability of serum immunoglobulin $\mathrm{G}$ responses to periodontal bacteria. J Clin Periodontol 2004:31:985-90. 